\title{
Magdalena Pancewicz-Puchalska
}

\section{Ekonomia daru, estetyka sztuczek, etyka uporu. Praktyki życia codziennego według Michela de Certeau}

Abstrakt: Autorka podejmuje temat praktyk w pracy Wynaleźć codzienność. Sztuki działania Michela de Certeau. Francuski filozof - dystansując się od koncepcji habitusu Pierre'a Bourdieu i teorii władzy i podmiotu Michela Foucault — buduje własne, intrygujące, lecz nieco nieuchwytne rozumienie praktyk jako aktywności, które czynią ludzkie życie znośnym, mimo ucisku społecznych struktur i kulturowych reguł. Autorka analizuje jego rozróżnienie między strategiami i taktykami i zaprasza czytelnika do spojrzenia na kulturę popularną jako sferę wynajdywania, ekonomii daru i etyki uporu (raczej niż oporu), a następnie do przemyślenia użyteczności tej perspektywy w aspekcie nauk o kulturze i społeczeństwie, a ostatecznie jej znaczenia dla naszej egzystencji.

Słowa-klucze: życie codzienne, praktyka, taktyka, strategia, ekonomia daru, opór, habitus

Praca Michela de Certeau Wynaleźć codzienność. Sztuki działania może być traktowana jako wyraz antyelitarnego ujmowania kultury, czyli takiego, które rezygnuje z podziału na kulturę wysoką i niską. Autentyczną, twórczą i wartościową z jednej oraz nieautentyczną, odtwórczą lub nietwórczą i bezwartościową $\mathrm{z}$ drugiej strony ${ }^{1}$. Certeau, intelektualista o szerokich zainteresowaniach — psychoanalityk, historyk, filozof i jezuita ${ }^{2}$ - rozwinął w niej interesujące, złożone,

${ }^{1} \mathrm{Z}$ tego względu koncepcja Certeau bywa zestawiana ze studiami kulturowymi i omawiana w opracowaniach im poświęconym — zob. na przykład V. Krönert, Michel de Certeau: Alltagsleben, Aneignung und Widerstand, [w:] Schlüsselwerke der Cultural Studies, red. A. Höpp, F. Krotz, T. Thomas, Wiesbaden 2009. Warto też zwrócić uwagę, że ich współzałożyciel, Raymond Williams, już w roku 1958 napisał esej zatytułowany Culture is ordinary. Prezentując założenia brytyjskich cultural studies, to sformułowanie wykorzystała Anna Kowalska (Nowy odbiorca? Przemiany obrazu odbiorcy w wybranych koncepcjach wspótczesnej kultury, Warszawa 2014, s. 53-55). Jedna z części książki Wynaleźć codzienność z kolei nosi tytuł Bardzo zwykła kultura.

${ }^{2}$ Osobnego rozpatrzenia wymagałyby pisma religijne i religioznawcze Certeau, zob. idem, Opętanie w Loudun, przeł. K. Przyłuska-Urbanowicz, Warszawa 2014. Szerzej traktuje o tym książka Daniela Bognera, Gebrochene Gegenwart: Mystik und Politik bei Michel de Certeau, Ostfildern 2002. O znaczeniu prac Certeau dla rozwoju socjohistorycznych badań religioznawczych 
wieloznaczne, a także cechujące się pewną nieuchwytnością podejście do praktyk życia codziennego ${ }^{3}$. Przeciwstawia się w niej obrazowi pasywnego, skazanego na bierną recepcję konsumenta i traktowaniu władzy jako wszechobejmującej. Nawiązuje w tym kontekście polemicznie do refleksji Michela Foucault dotyczącej relacji władzy i podmiotu ludzkiego (zwłaszcza do tego, jak ujęte to zostało w jego książce Nadzorować $i$ karać). Sytuuje także swój projekt — jeśli nie w opozycji to w pewnym dystansie do teorii praktyki i praktyki teorii Pierre'a Bourdieu. Certeau śledzi ścieżki kreatywności i oporu wyznaczane przez praktyki, które nie są rewolucyjne, czytelne czy łatwo dostrzegalne, a raczej ciche, rozproszone i jakby niewidoczne ${ }^{4}$. Niemniej zaznacza, że nie jest jego zamiarem tworzenie teorii podmiotu. Interesuje go raczej „operacyjna logika” praktyk, zespołów czynności stanowiących „pewnego rodzaju »kulturę《"s. Kulturę tak zwanych konsumentów, których marginalność staje się dziś większością:

W technokratycznie skonstruowanej, zapisanej i funkcjonalnej przestrzeni trajektorie, po których poruszają się konsumenci, tworzą nieprzewidywalne zdania, częściowo nieczytelne „drogi w poprzek". Mimo że zbudowane ze słów w istniejących językach i zgodnie z zasadami składni, kreślą one podstępy odnoszące się do innych celów i pragnień nieokreślonych ani nieuchwyconych przez systemy, w obrębie których powstają ${ }^{6}$.

Zadanie Certeau jest, jak sam deklaruje, zarazem analogiczne i przeciwstawne do teoretycznych osiągnięć Foucault:

analogiczne, ponieważ chodzi o wyszczególnienie mikroskopijnych czynności, które, mnożąc się w obrębie technokratycznych struktur, przechwytują ich funkcjonowanie dzięki ogromnej liczbie „taktyk” [...]; przeciwstawne, ponieważ nie chodzi o określenie, w jaki sposób przemoc porządku przekształca się w technologie dyscyplinarne, ale o wydobycie ukrytych form, jakie przybiera rozproszona, taktyczna i ,amatorska” twórczość grup lub jednostek pochwyconych odtąd w sieci ,nadzoru”?

Zadanie polegałoby zatem na nakreśleniu pewnej mikrofizyki, ale mikrofizyki oporu raczej niż władzy. Władza, według autora Nadzorować i karać, od XVIII wieku przybiera postać rozproszoną. Uosabiana przez techniki dyscyplinarne rozsiane $\mathrm{w}$ szpitalach, szkołach, więzieniach czy miejscach pracy, jest niewidocz-

wspomina u nas Andrzej Wójtowicz (Kulturowa socjologia religii w perspektywie religioznawstwa porównawczego, „Przegląd Religoznawczy” 2011, nr 3). Zob. też S. Obirek, Michel de Certeau szkoda, że tak mało znany, „Miesięcznik Ewangelicki” 2014, nr 13-14.

${ }^{3}$ Zob. The Certeau Reader, red. I. Buchanan, Manchester 2000, s. 97-98. Ponadto J. Skurtys, Praktyki codziennego oporu. Everyday life studies jako teoria sprzeciwu, [w:] Opór - protest wykroczenie, red. Ł. Janicki, J. Wach, Lublin 2015. Ten ostatni artykuł jest też ciekawy z uwagi na odnotowanie dość już usamodzielnionych $\mathrm{w}$ anglosaskim świecie naukowym everyday life studies.

${ }^{4}$ Zob. M. de Certeau, Wstęp ogólny, [w:] idem, Wynaleźć codzienność. Sztuki działania, przeł. K. Thiel-Jańczuk, Kraków 2008, s. XXXVI.

${ }^{5}$ Ibidem, s. XXXV.

${ }^{6}$ Ibidem, s. XLI.

${ }^{7}$ Ibidem, s. XXXVIII. 
na, a pragnie obejmować wszystko swym wzrokiem i działaniem. Od epoki klasycznej mamy do czynienia ze społeczeństwem dyscyplinarnym, od tego czasu „Benthamowska fizyka władzy jest tylko konstatacją faktów”8.

Wobec tej wizji Certeau jednak stawia kilka zasadniczych pytań, które krążą wokół jednej kwestii:

a) Jak wyjaśnić uprzywilejowany rozwój owej szczególnej serii, jaką stanowią urządzenia panoptyczne?

b) Jaki jest status tylu innych serii, które, podążając cicho własną drogą, nie stworzyły okazji ani do ich dyskursywnego ukształtowania, ani do technologicznej systematyzacji? Mogłyby być one traktowane jako olbrzymia rezerwa stanowiąca zalążki lub ślady rozmaitych rozwinięć 9 .

Zdaniem Certeau błędem było uznanie przez Foucault, że możliwe jest zredukowanie życia społeczeństwa do dominującego typu procedur. Poza lub pod tkanką praktyk normatywnych i znormalizowanych, umożliwiających dyskurs nauk humanistycznych, rozciąga się ,„»politeizm《 rozproszonych praktyk”" ${ }^{\prime 10}$ jak je określa: „mniejszych”, które nie zapisały się w historii, nie tworzą dyskursu. Podobnie - wbrew zapewnieniom Foucault, że władza nie ma właściwego sobie locus, nie jest domeną instytucji - Certeau twierdzi, że spojrzenie na diagnozę, jaką przedstawił autor Narodzin kliniki, w szerszej perspektywie skłania do zanegowania tego twierdzenia: techniki władzy wymagają i są w posiadaniu własnego miejsca w przeciwieństwie do taktyk konsumentów. Ma tu z pewnością na myśli podział i opanowanie przestrzeni, jakiej dokonują dyscypliny, jej „parcelację”. Odgrywa ona istotną rolę w działaniu tego rodzaju władzy:

Każdemu — jego miejsce, w każdym miejscu — ktoś [...]. Trzeba mieć informacje o obecności i nieobecności, wiedzieć, jak i kiedy każdego znaleźć, umożliwić kontakty pożyteczne a przeciąć szkodliwe, móc w każdej chwili nadzorować zachowanie każdego, ocenić je, zareagować, wyliczyć zalety i zasługi. A zatem procedura — by poznać, opanować i wykorzystać ${ }^{11}$.

A zatem strategia - powiedziałby Certeau. Aż i tylko strategia. Taktyki, praktyki pozbawione własnego miejsca, niezdolne do panowania i kumulacji własnych osiągnięć, wymykają się albowiem strategicznemu imperatywowi.

Zanim jednak przejdę do charakterystyki tych dwóch rodzajów praktyk, rozpatrzę najpierw przeprowadzoną przez Certeau krytykę Bourdieu, a następnie zarzuty wobec niego i Foucault, dotyczące ich metodologii. Taki tok wywodu podyktowany jest faktem, że Certeau dostrzega jeden sposób naukowego postępowania cechujący obu tych autorów.

Bourdieu interesuje Certeau przede wszystkim jako twórca teorii habitusu, którą to nazwą ten pierwszy określa „system trwałych dy spozycji”, a, definiu-

${ }^{8}$ M. Foucault, Nadzorować i karać. Narodziny więzienia, przeł. T. Komendant, Warszawa 1998, s. 204.

${ }^{9}$ M. de Certeau, Wynaleźć codzienność, s. 49.

10 Ibidem, s. 50.

${ }^{11}$ M. Foucault, op. cit., s. 138. 
jąc szerzej, są to „struktury ustrukturowane i predysponowane do działania jako struktury strukturujące, tzn. jako zasada generowania i strukturowania praktyk i wyobrażeń" 12 . Autor Wynajdywania codzienności zwraca uwagę na kołowy ruch teorii, którego zresztą Bourdieu jest świadomy. Jak bowiem sam ujmował:

Praktyki, wytwarzane przez habitus jako generator strategii pozwalających stawić czoła nieprzewidzianym i wciąż nowym sytuacjom, [są zdeterminowane - M.P.P.] przez niegdysiejsze warunki wytworzenia ich zasady produkcji i dlatego zawsze dążą do odtworzenia obiektywnych struktur, których w ostatecznej analizie są wytworem ${ }^{13}$.

Konsekwencją takiego ujęcia jest odebranie praktykom impulsu twórczego, zdolności wynajdywania, a pozostawienie tej roli wyłącznie strukturom. W wyniku tak postrzeganej praktyki nic nowego się nie zdarza:

ani rozszerzenie gustu poprzez przypadkowe odkrycie (posłyszana melodia w radiu, która zwróci uwagę, afisz w nowym stylu graficznym, który przykuje spojrzenie), ani pozostawiające ślad spotkanie z nowym rozmówcą, które umożliwi poznanie innych praktyk kulturowych, ani osobiste pragnienie samokształcenia w takiej lub innej dziedzinie estetycznej. Można by rzec, posługując się terminologią Karla Poppera, że teoria Bourdieu jest niezbita, ponieważ nie można jej „,falsyfikować”: nie może się przydarzyć żaden „nieprzewidziany” fakt, który byłby niemożliwy do zinterpretowania w teorii i mógłby zachwiać jej podstawą ${ }^{14}$.

Praktyki są niemal całkowicie ograniczone, a nawet zdeterminowane przez obiektywne warunki i logikę pól. I w przypadku koncepcji Bourdieu, twierdzi Certeau, dominuje tematyka miejsca: jako dziedzictwa (przez co Certeau rozumie regułę habitusu, skłaniającą do nieustannej akumulacji kapitału) i rozwoju (a może należałoby powiedzieć — reprodukcji) ciała jednostkowego i zbiorowego. Ostatecznie habitus jest „miejscem dogmatycznym” 15 .

Certeau zastanawia retoryka tekstów Bourdieu, który wiele wysiłku wkłada w to, aby skrupulatnie opisać swoisty spryt praktyk, ich nieuchwytną i niezapisywalną „wirtuozerię", po czym opisy te zwieńcza teoretycznymi wywodami, których kategoryczność nie dopuszcza powątpiewania. Certeau widzi w tym gest wychodzenia — ku podstępnym taktykom — i powrotu — do racjonalności nauki. Stawia sprawę bardzo poważnie i zarazem przewrotnie, pytając:

Czyż jednak ów pośpieszny powrót nie świadczy o jego znajomości, śmiertelnego być może, niebezpieczeństwa, na jakie naukowa wiedza zostaje wystawiona przez owe nazbyt inteligentne praktyki? ${ }^{16}$

12 P. Bourdieu, Szkic teorii praktyki, poprzedzony trzema studiami na temat etnologii Kabylów, przeł. W. Kroker, Kęty 2007, s. 193.

${ }^{13}$ Ibidem. Zob. też P. Bordieu, Zmyst praktyczny, przeł. M. Falski, Warszawa 2008, s. 72-90, $110-134$.

${ }^{14}$ L. Giard, Gotować, [w:] M. de Certeau, L. Giard, P. Mayol, Wynaleźć codzienność. 2. Mieszkać, gotować, przeł. K. Thiel-Jańczuk, Kraków 2011, s. 168.

15 M. de Certeau, Wynaleźć codzienność, s. 60.

16 Ibidem, s. 61. 
Aby uciec przed tym niebezpieczeństwem i móc rościć sobie pretensje do naukowego, dyskursywnego uchwycenia prawdy praktyk, Bourdieu hipostazuje w postaci habitusu niewidzialny i nieweryfikowalny „byt”. Okazuje się, że społeczeństwo może być systemem tylko za cenę nieświadomości. Certeau widzi w tym powrót do tradycyjnej etnologii, która - jego zdaniem — zawsze przypisywała jakiejś wyizolowanej grupie spójność i nieświadomość. Dlatego autor Regut sztuki w obręb swego socjologicznego myślenia musiał wprowadzić elementy etnologiczne ${ }^{17}$. Bourdieu, który często przedstawiał siebie jako postać przełomową w dziedzinie nauk społecznych, mógłby być niemało zdziwiony tą oceną. W ten sposób Certeau dochodzi do krytycznego i zaskakującego być może wniosku: dyskurs Bourdieu w nieświadomości praktykuje to, co wie, jest zatem w końcu samą ,uczoną niewiedzą”, jaką, według socjologa, mają być nieświadomie inteligentne działania generowane przez habitus.

Krytyka poglądów Foucault i Bourdieu u Certeau nie ogranicza się do przywołanych przeze mnie uwag, te wydają się jednak najistotniejsze z mojego punktu widzenia. Analitycznie rzecz ujmując, można stwierdzić, że jedna ich grupa dotyczy pewnego przeoczenia czy wyparcia: wyparcia inwencyjności praktyk życia codziennego. Druga część zarzutów Certeau wobec obu wskazanych wyżej badaczy odnosi się do wspólnych im procedur naukowego postępowania, do gestu metonimizacji, którą ujmuje w formułę „najpierw wykroić, następnie przenicować"18. Obaj, zdaniem Certeau, wybierają pewien typ praktyk z ich ogromnej ilości, uznając przy tym, że reprezentują one (niemożliwą do ogarnięcia) całość i pozwalają wszystko wyjaśnić. W przypadku Foucault to procedury nadzoru i dyscypliny „przyczyniają się do zrozumienia zarówno organizacji naszego społeczeństwa, jak i nauk społecznych"19. Z kolei strategie zdobywania kapitału, utożsamiane przez Bourdieu z habitusem, mimo że są „podstępne, wielopostaciowe" i jakoby niedostępne naukowej racjonalności, stają się elementem centralnym wyjaśniającego dyskursu ${ }^{20}$. Ową niewspółmierność potwierdzają częste wyjaśnienia, komentarze i zastrzeżenia Bourdieu towarzyszące tworzonym przez niego diagramom, schematom, tabelom. Nierozdzielne od owych chwytów i uników, przekonuje Certeau, są retoryczne aspekty pisarstwa obu autorów. Styl Bourdieu jest „pokrętny i zawiły”, obfituje w „monotonne powtarzające się stwierdzenia, dziwne połączenie sformułowań typu: »jestem przekonany« [...] oraz »ale jednak «"21. Pisanie Foucault natomiast wyróżnia

\footnotetext{
17 Zob. ibidem, s. 57-58.

18 Ibidem, s. 64

19 Ibidem, s. 65.

${ }^{20}$ Ibidem.

${ }^{21}$ Ibidem, s. 60.
} 
sztuka suspensu, cytatów, elipsy i metonimii; sztuka koniunktury (aktualności, publiczności) oraz sposobności (epistemologicznych, politycznych); ogólnie mówiąc, sztuka „robienia sztuczek" za pomocą fikcji historycznych ${ }^{22}$.

Zestawienie obrazów historycznych oraz analitycznych rozróżnień wywołuje w czytelnikach poczucie oczywistości.

Niezależnie od tego, czy zgadzamy się z Certeau co do oceny Foucault i Bourdieu, czy nie, jest ona interesująca z kilku względów: nie tylko jako krytyka tych dwóch wpływowych w humanistyce postaci, lecz także jako odkrycie miejsca, z którego Certeau ją wypowiada, oraz jako apologia oporu, jaki stawiają władzy praktyki życia codziennego. Ujawniałaby się tu pewna dialektyka oddzielenia — dystansowanie się od poglądów tych badaczy poprzedza przyswojenie i częściowa akceptacja. Relacja między Certeau i Foucault oraz Certeau i Bourdieu przypomina związek, jaki Georg Steiner dostrzega między Sokratesem a Protagorasem i Gorgiaszem: ,zawiły splot ironii i szacunku, odrzucenia i mimesis" 23 . Luce Giard przypomina jednak, że większość pojęć i tez składających się na $W y$ naleźć codzienność. Sztuki działania pojawiała się już w tekstach Certeau napisanych przed wydaniem Nadzorować i karać. Co więcej, Luce Giard, uczeń i współpracownik Certeau, twierdzi, iż niezgoda na teoretyczne propozycje Foucault i Bourdieu u jego mistrza wynika z czegoś, co poprzedza teorię: z pewnego rodzaju nastrojenia wobec otaczającej rzeczywistości, sposobu bycia w świecie cechującego się otwartością, wyczuleniem i skłonnością do zachwytu w obliczu nawet najmniejszych przejawów wolności ludzi umieszczonych zawsze w ramach jakiegoś porządku ${ }^{24}$.

Wizja praktyk Certeau jest zatem uwarunkowana przeddyskursywnym nastawieniem (czy tylko jego wizja ma takie podłoże?), ale — podobnie jak krytykowani przez niego uczeni - podjął się karkołomnego zadania utrzymania dyskursywnej relacji z tym, co niedyskursywne (praktykami). Nie jest on myślicielem ani pisarzem systematycznym, co nie wyklucza oczywiście rygoryzmu czy rzetelności. Od Kanta przejmuje ideę, że zarówno teoria, jak i praktyka wymagają umiejętności sądzenia, która tworzy pewną sztukę - sztukę linoskoczka. Sam więc, jako twórca teorii, praktykuje sztukę, która, starając się podążać za tym, co jest nie do opanowania w sposób teoretyczny, staje się podobnie trudno uchwytna.

Zanim przejdę do zarysowania wizji praktyk Michela de Certau, chciałabym zwrócić uwagę, że posługuje się on pojęciem konsumenta, które nie zajmuje wyróżnionej pozycji w słowniku Foucault. Bardziej pasowałoby ono do terminologicznego repertuaru Bourdieu, badającego społeczną konstrukcję smaku i prak-

\footnotetext{
22 Ibidem, s. 80.

${ }^{23}$ G. Steiner, Nauki Mistrzów, przeł. J. Łoziński, Poznań 2007, s. 21.

${ }^{24}$ Zob. L. Giard, Wprowadzenie, [w:] M. de Certeau, Wynaleźć codzienność, s. XVIII-XIX.
} 
tyki konsumpcji sztuki ${ }^{25}$. Czy Certeau nie myli pojęć, a w konsekwencji czy nie dezinterpretuje teorii Foucault? Sieć dyscypliny i nadzoru częściowo pokrywa się u niego z tym, co obejmuje ona u Foucault. Intryguje go jednak sieć telewizyjna, urbanistyczna, komercyjna, handlowa czy przemysłowa, nie zaś, na przykład, kliniczna czy więzienna. Ponadto, w książce Wynaleźć codzienność koncentruje się głównie na zjawiskach typowych dla XX wieku. Nie jest moim zamiarem pytanie o „wierność” tej lektury. Zaznaczam tylko, że Certeau przemieszcza debatę na nieco inną niż wyznaczona przez autora Historii seksualności płaszczyznę, nie zatrzymując się nad tym faktem, nie poddając go uzasadniającej refleksji. Według mnie jest to płaszczyzna sporu o produktywność kultury konsumentów.

Konsument, uważa Certeau, postrzegany jest jako pasywny, jako że nauki, które w głównej mierze ukształtowały ten wizerunek, przedmiotem swojego namysłu czynią zwykle wytwory i reprezentacje zamiast praktyk, użyć przedmiotów, reprezentacji i wyobrażeń. Podobnie jak Karol Marks we Wprowadzeniu do krytyki ekonomii politycznej, choć z innych powodów, wskazuje, iż podział na produkcję i konsumpcję jako odrębne i różne od siebie procesy należy podać w wątpliwość ${ }^{26}$. Zachowanie konsumentów jest swego rodzaju produkcją, nie w tym sensie, że coś tworzy, ale przez ponowne użycie i rekombinowanie materiałów, przez bricolage:

Owo interesujące nas ,wytwarzanie” jest produkcją, poietyką (poiétique), lecz ukrytą, ponieważ rozprasza się ona w rejonach zdefiniowanych i okupowanych przez systemy ,produkcji” (telewizyjnej, urbanistycznej, handlowej itd.), a coraz bardziej całościowy zakres owych systemów nie pozostawia „konsumentom” miejsca, w którym mogliby zaznaczyć, co robia z produkta$\mathrm{mi}^{27}$.

Szkolny podręcznik nie jest przeznaczony do pisania i rysowania w nim, jednak dziecko to czyni i „określa w ten sposób własną przestrzeń, w której zaznacza się jego istnienie jako autora" ${ }^{28}$. Trzeba przyznać, że nie jest to imponujący ani spektakularny przykład ,oporu”. Umiejętność dostrzegania i doceniania tych małych ruchów jako znaczących wymaga jednak zmiany perspektywy ${ }^{29}$.

Ben Highmore, autor książki Everyday Life and Cultural Theory, uważa, że Certeau nie tworzy i nie nakłania do tworzenia ,katalogu drobnych subwersji (po-

25 Zob. P. Bourdieu, Dystynkcja. Społeczna krytyka władzy sądzenia, przeł. P. Biłos, Warszawa 2005.

26 Zob. K. Marks, Wprowadzeniu do krytyki ekonomii politycznej, przeł. E. Lipiński, [w:] idem, Człowiek i socjalizm. Pisma wybrane, Warszawa 1979, s. 516-523.

${ }^{27}$ M. de Certeau, Wynaleźć codzienność, s. XXXVI.

28 Ibidem, s. 32.

${ }^{29}$ Koncepcją Certeau inspirują się i wykorzystują ją empirycznie Sławomir Sikora i Karolina J. Dudek, Aktywności miejskie. Kierunek Grochów, [w:] Nowe kłopoty z kultura, red. S. Sikora, K.J. Dudek, Warszawa 2016. Książka ta jest jedynym z efektów realizowanego w Instytucie Etnologii i Antropologii Uniwersytetu Warszawskiego projektu badawczego „Oddolne tworzenie kultury” (zob. http://kulturaoddolna.pl/). 
szarpane jeansy, skateboarding itd.)"30, próbuje raczej stworzyć „,skrzynkę z takimi narzędziami [tool kit]", które uwidocznią niezwykłość codzienności i pozwolą dosłyszeć jej polifonię. Nie są to narzędzia standaryzowalne i dlatego sądzę, że za każdym razem piszący o praktykach musi sam zdecydować, co jest taktyką, a co elementem systemu lub na przykład przestępstwem. Inna komentatorka prac Certeau wywodzi z nich i rozwija analogię, która pomaga zilustrować wspomnianą zmianę perspektywy. Jak - pyta — odróżnić bezinteresowny dar od elementu obowiązkowego cyklu wymian? Claire Colebrook odpowiada: prawie nic nie odróżnia ekonomii daru od standardowej ekonomii wymiany, „tym, co różni dar, jest to, że nie spogląda się na niego z punktu widzenia wymiany" ${ }^{11}$. Ta analogia uwidacznia inną cechę praktyk: dar nie powinien być sytuowany, ma być jedynie rozpoznany. Jak za Jacques'em Derridą zauważa Colebrook, gdyby dar był sytuowany w cyklu obowiązków, straciłby swój status czegoś nadmiernego. Przywołana badaczka rozwija taką koncepcję taktyk jako metafor oraz kwestię ich relacji do dominującego porządku i tego, co dosłowne:

Zatem, mówiąc ściśle, nie są one taktykami czy metaforami; stają się nimi tylko, gdy na codzienne ruchy czy słowa (odpowiednio) patrzy się jak na taktyki czy metafory, albo gdy postrzega się je nie jako to, czym są naturalnie i dosłownie, ale jako wydarzenia w pewnym stylu. Kiedy tak się na nie patrzy, uchwytuje się nie jakiś nowy obiekt czy czyste zewnętrze, ale ścisłą immanencję [the strictly immanent] postrzega jako ruch przekraczający immanencję ${ }^{32}$.

Jest to oczywiście jej interpretacja. Wydaje się, że pociąga za sobą ryzyko pomniejszenia różnicy między taktykami a strategiami.

U Certeau posiadanie własnego miejsca (le lieu propre) jest rysem strategii, nieposiadanie go — taktyki:

Nazywam strategia rachunek stosunków sił [...], powstający z chwilą, gdy możliwe jest wyodrębnienie podmiotu woli i władzy (takich jak przedsiębiorstwo, armia, miasto, instytucja naukowa). Strategia zakłada istnienie miejsca, które mogłoby być opisane jako własność (un propre) i stanowić podstawę do regulowania stosunków z zewnętrznością, w której sytuują się cele i zagrożenia (klienci lub konkurencja, wrogowie, wieś w pobliżu miasta, cele i przedmioty badań itp.) ${ }^{33}$.

Poza przestrzenią fizyczną Certeau wyróżnia miejsca teoretyczne (systemy i totalizujące dyskursy) oraz miejsca władzy. Formuła le lieu propre powiązana

${ }^{30}$ B. Highmore, Everyday Life and Cultural Theory. An Introduction, London-New York 2002, s. 171. Zob. również idem, Michel de Certeau: Analysing Culture, London-New York 2006. Ten uczony zredagował też wybór tekstów poświęcony historycznym koncepcjom życia codziennego, w którym, oczywiście, znalazło się miejsce na poglądy Certeau (The Everyday Life Reader, red. B. Highmore, New York 2001). Bardziej systematyczną i autorską wypowiedź Highmore'a stanowi książka Ordinary Lives. Studies in the Everday, New York 2011.

31 C. Colebrook, Certeau and Foucault: Tactics and Strategic Essentialism, „The South Atlantic Quarterly" 2, 2001, s. 557.

32 Ibidem, s. 547.

${ }^{33}$ M. de Certeau, Wynaleźć codzienność, s. 36. 
jest z innymi terminami: własność, właściwość, posiadanie, dosłowność. Własność (un propre) jest domeną władzy i wiedzy:

Strategie wojskowe czy naukowe powstawały z chwilą utworzenia „własnych” miejsc (niezależnych miast), „neutralnych” lub „,niezależnych” instytucji, „bezstronnych” laboratoriów badawczych ${ }^{34}$.

Wyznaczenie własnego miejsca to ,gest kartezjański. Gest typowy dla naukowej, politycznej, czy wojskowej nowoczesności" ${ }^{35}$. W tym zakresie, jak widzimy, Certeau przyswoił lekcję Foucault. Strategie opisuje jako procedury władzy-wiedzy, która umożliwia gromadzenie zdobytej przewagi, dzięki uniezależnianiu się od czasu i sposobności, oraz panującą za pomocą wzroku ${ }^{36}$, kontrolującą obce jej siły, zdolną do przewidywania.

Taktyka, „sztuka słabego”, może działać tylko w miejscu innego:

dlatego musi ono wykorzystywać obszar jej narzucony i zorganizowany przez prawo siły obcej [...]. Nie ma więc możliwości stworzenia dla siebie całościowego planu działania ani ujarzmienia przeciwnika w innej, widocznej i obiektywnie istniejącej przestrzeni.

Ta praktyka nie-miejsca (non-lieu) zależy od czasu:

Dostosowuje się do sytuacji. Korzysta ze „sposobności” i od nich zależy, nie posiadając bazy, w której mogłaby zdobywać przewagę, powiększać własność i planować ataki ${ }^{37}$.

Jako że nie ma własnego miejsca, nie może też wydzielać zewnętrzności, co jest warunkiem autonomii. Jednak dzięki temu cechuje ją mobilność i podstępność. Taktyka jest zdolnością wykorzystywania narzuconej logiki do swych celów. Jednak - co podkreśla Colebrook - taktyka ani nie tworzy innego, ani całkowicie nie przekracza strategicznego porządku, należy do procedur „różnorodnych, niepokornych, przebiegłych i uporczywych — które wymykają się dyscyplinie, pozostając jednak w polu jej działania"38. Konsument jest rodzajem imigranta, powiada Certeau. Metafora ta ma obrazować mechanizm bycia jednocześnie schwytanym w dany porządek i niepasowanie do niego:

Taktyki mnożą się w naszych społeczeństwach [...] upodabniając konsumentów do imigrantów błądzących w systemie zbyt rozległym, aby go opanować, i zarazem zbyt ścisłym, aby się z niego wyrwać ${ }^{39}$.

${ }^{34}$ Ibidem, s. 37.

35 Ibidem, s. 36.

${ }^{36}$ Szerzej o tym traktuje opracowanie Taktyki wizualne. Michel de Certeau i obrazy, red. J. Thiel-Jańczuk, Kraków 2016. Zamieszczone w nim zostały także prace samego Certeau: Szaleństwo widzenia. Widzialne i niewidzialne, przeł. B. Brzezicka; Ogród: delirium i rozkosz Hieronima Boscha, przeł. K. Thiel-Jańczuk; Biała ekstaza (przeł. K. Thiel-Jańczuk).

${ }^{37}$ M. de Certeau, Wynaleźć codzienność, s. 37.

38 C. Colebrook, op. cit., s. 98.

${ }^{39}$ M. de Certeau, Wynaleźć codzienność, s. XLIII. 
Jako przykłady taktyk Certeau podaje czynności, takie jak czytanie ${ }^{40}$, gotowanie, przemieszczanie się, robienie zakupów, zamieszkiwanie. Jednym z bardziej sugestywnych jest tzw. la perruque, ,peruka”. To francuskie słowo opisuje zjawisko polegające na wykorzystywaniu czasu w pracy (urzędzie, biurze, fabryce) dla siebie, nie zaś dla pracodawcy: sekretarka w godzinach pracy pisze list miłosny na sprzęcie należącym do firmy, robotnik wytwarza z resztek jakiś przedmiot, który planuje zabrać do domu. Dziś ,,peruką” prawdopodobnie najbardziej typową jest surfowanie po Internecie. Te sposoby radzenia sobie (faire avec, make do), przechwytywania, „kłusowania” są, zdaniem Certeau, powszechne. Reakcje zwierzchników wahają się od karania do ignorowania. La perruque jest dywersją w łonie ekonomii zysku: „To właśnie stanowi kulturę »popularną «"41: ekonomia daru, estetyka sztuczek i etyka uporu:

Rzeczywistym porządkiem rzeczy jest jednak to, co praktyki „ludowe” przechwycą dla siebie, nie łudząc się, że ów porządek tym samym się zmieni. Podczas gdy dominująca władza go eksploatuje, a ideologiczny dyskurs odrzuca, tutaj jest on wykorzystywany przez sztukę. Do instytucji wkrada się w ten sposób styl społecznych wymian, styl technicznych inwencji oraz styl oporu moralnego, to znaczy pewna ekonomia daru (wzajemne dobrodziejstwa), estetyka sztuczek (działania artystów) oraz etyka uporu (niezliczone sposoby odmawiania ustalonemu porządkowi statusu prawa, sensu czy nieuchronności $)^{42}$.

Taktyką jest także chodzenie po mieście. Certeau przeciwstawia je pragnieniu objęcia wzrokiem panoramy miasta (i koncepcji miasta w ogóle). Posiadanie „wszechogarniającego oka” było pragnieniem malarzy średniowiecznych i renesansowych na długo przed tym, jak jego zrealizowanie umożliwiły zdobycze współczesnej architektury — drapacze chmur. Piesi natomiast piszą tekst, złożoną historię, który nie ma czytelnika, ani widza, i jest ,inny” wobec reprezentacji. Spacerowanie nie panuje nad przestrzenią z wysoka, lecz rozwija się w czasie i wyznaczane jest jednostkowymi wyborami. Mapy i zapisy ścieżek — wynalazki strategiczne - gubią to, co najistotniejsze:

sam akt przechodzenia. Czynność chodzenia, błądzenia czy „oglądania sklepowych wystaw”, [...] czynność przechodniów, zostaje przemieniona w punkty, stanowiąc na planie scalającą i odwracalną linię ${ }^{43}$.

Zarysowana opozycja wynika z istotnego rozróżnienia, zaczerpniętego, na co wskazuje sam Certeau, od Maurice'a Merleau-Ponty'ego: na przestrzeń geometryczną — skonstruowaną przez urbanistów i architektów — oraz antropologiczną przestrzeń „poezji, legend i pamięci”44. W porównaniu praktyk z aktywami

${ }^{40} \mathrm{O}$ możliwych użytkach z koncepcji Certeau dla literaturoznawstwa zob. J. Skurtys, Doświadczenie lektury wobec praktyk codzienności (od afirmacji do kontestacji), „Czytanie Literatury. Łódzkie Studia Literaturoznawcze" 2014.

${ }^{41}$ M. de Certau, Wynaleźć codzienność, s. 28.

42 Ibidem.

43 Ibidem, s. 98.

44 V.A. Conley, Processual Practices, „The South Atlantic Quarterly”2, 2001, s. 486. 
mowy, które rozwija Certeau, przestrzeń geograficzna czy geometryczna odpowiada dosłownemu sensowi, które gramatycy i językoznawcy przypisują językowi, ,jako normalny i normatywny poziom, do którego można by odnieść różnice sensu »przenośnego« (sens fiduré)" "45. Certeau zaś utrzymuje, nawiązując do filozofii języka Ludwiga Wittgensteina ${ }^{46}$, że w rzeczywistości znaczenie dosłowne i właściwe jest fikcją, której nie spotka się w codziennym użyciu ani w wypowiedzi werbalnej, ani „pieszej”. Taktyka chodzenia zmienia pierwotny, właściwy sens nazw ulic, przypisując im znaczenia i wiążąc z emocjami zakorzenionymi w indywidualnym doświadczeniu: poetycka geografia przysłania geografię dosłownego. Pojawia się tu kategoria pamięci - pamięć kształtująca ludzką przestrzeń. Certeau zwraca naszą uwagę na powszechne, ale zarazem intrygujące zjawisko: „miejsca, w których żyjemy, są jakby obecnościami nieobecności”47. „Tu mieszkała pani X”, „Tu była kawiarnia”, myślimy, przemierzając miasto. Tylko miejsca „nawiedzone” są mieszkalne i to nawiedzenie, zdaniem Certeau, odwraca schemat Panoptikonu.

Praca Wynaleźć codzienność jest krytykowana za ślepotę na gender, za zagubienie się we własnym języku; za to, że nie proponuje teorii działania sprawczego (agency) przy aspirowaniu do dostarczania teorii oporu albo za nieaktualność w dobie przemysłu handlowego zorientowanego na niematerialne dobra i symboliczne walki toczące się na terenie życia codziennego itp. Być może stanowisko Certeau jest zbyt afirmatywne - wiele codziennie wykonywanych zwykłych czynności mianować można by taktykami, wiele z nich zatem podpadałoby pod kategorię „oporu”. Na pewno teza Certeau jest narażona na zarzut obrony lub zgody na status quo, który zawsze powinien być kontestowany w imię lepszej rzeczywistości. Być może kategoria ta jest przesadna, nieadekwatna. Mimo wszystko, według mnie, koncepcja Certeau stanowi wartościowy i inspirujący wkład w toczące się debaty na temat praktyk życia codziennego i ich inwencyjnego potencjału. Podobnie jak Jolanta Brach-Czaina w dobrze znanych Szczelinach istnienia $^{48}$ przypisuje on sens i wagę temu, co jest ich (rzekomo) pozbawione. A może to my, jak sugerowała przywołana autorka, pozbawiamy czegoś istotnego siebie i innych (nie troszcząc się o ich zdanie), gdy wzbraniamy się przed przyznaniem znaczenia, stylu, twórczej nieproduktywności codziennym czynnościom, i ich nieczytelnym ścieżkom?

${ }^{45}$ M. de Certeau, Wynaleźć codzienność, s. 102.

46 O stosunku Certeau do Wittegensteina zob. M. Sheringham, Michel de Certeau: odzyskać codzienność, przeł. B. Brzezicka, [w:] Taktyki wizualne. Jest to fragment jego książki Everyday Life: Theories and Practices from Surrealism to the Present, Oxford 2006.

47 M. de Certeau, Wynaleźć codzienność, s. 109.

48 Zob. J. Brach-Czaina, Szczeliny istnienia, Warszawa 1992. 


\section{Economy of the Gift, Esthetics of Tricks, Ethics of Tenacity. Michel de Certeau's on the Practices of Everyday Life}

\section{Abstract}

The author deals with the notion of practice in Michel de Certeau's The practice of everyday life. The French philosopher - distancing himself from Pierre Bourdieu's concept of habitus and Michel Foucault's theory of subject and power - builds his own which is appealing but somehow elusive understanding of practice as the activity of making our lives livable within the constraints of social structures and cultural rules. She analyses his distinction between strategies and tactics and invites the reader to try out the perspective on popular culture as a space of invention, economy of gift and ethics of stubbornness (rather than resistance) and finally to take a step back and rethink its usefulness for social and cultural sciences and lastly it's sense for our existence.

Keywords: everyday life, practice, tactic, strategy, economy of gift, resistance, habitus

\section{Bibliografia}

Bogner D., Gebrochene Gegenwart: Mystik und Politik bei Michel de Certeau, Ostfildern 2002. Bourdieu P., Dystynkcja. Społeczna krytyka władzy sądzenia, przeł. P. Biłos, Warszawa 2005.

Bourdieu P., Szkic teorii praktyki, poprzedzony trzema studiami na temat etnologii Kabylów, przeł. W. Kroker, Kęty 2007.

Bourdieu P., Zmyst praktyczny, przeł. M. Falski, Kraków 2008.

Brach-Czaina J., Szczeliny istnienia, Warszawa 1992.

Certeau M. de, Opętanie w Loudun, przeł. K. Przyłuska-Urbanowicz, Warszawa 2014.

Certeau M. de, Wynaleźć codzienność. Sztuki działania, przeł. K. Thiel-Jańczuk, Kraków 2008.

Certeau M. de, Giard L., Mayol P., Wynaleźć codzienność. 2. Mieszkać, gotować, przeł. K. Thiel-Jańczuk, Kraków 2011.

The Certeau Reader, red. I. Buchanan, Manchester 2000.

Colebrook C., Certeau and Foucault: Tactics and Strategic Essentialism, „The South Atlantic Quarterly" 2, 2001.

Conley V.A., Processual Practices, „The South Atlantic Quarterly” 2, 2001.

Foucault M., Nadzorować i karać. Narodziny więzienia, przeł. T. Komendant, Warszawa 1998.

Highmore B., Everyday Life and Cultural Theory. An Introduction, London-New York 2002.

Highmore B., Michel de Certeau: Analysing Culture, London-New York 2006.

Kowalska A., Nowy odbiorca? Przemiany obrazu odbiorcy w wybranych koncepcjach wspótczesnej kultury, Warszawa 2014.

Krönert V., Michel de Certeau: Alltagsleben, Aneignung und Widerstand, [w:] Schlüsselwerke der Cultural Studies, red. A. Höpp, F. Krotz, T. Thomas, Wiesbaden 2009.

Marks K., Wprowadzenie do krytyki ekonomii politycznej, przeł. E. Lipiński, [w:] idem, Człowiek i socjalizm. Wybór pism, Warszawa 1979.

Obirek S., Michel de Certeau — szkoda, że tak mało znany, „Miesięcznik Ewangelicki” 2014, nr $13-14$.

Sheringham M., Michael de Certeau: odzyskać codzienność, przeł. B. Brzezicka, [w:] Taktyki wizualne. Michael de Certeau i obrazy, red. J. Thiel-Jańczuk, Kraków 2016.

Sikora S., Dudek K.J., Aktywności miejskie. Kierunek Grochów, [w:] Nowe klopoty z kultura, red. S. Sikora, K.J. Dudek, Warszawa 2016.

Prace Kulturoznawcze XX, 2016

(C) for this edition by CNS 
Steiner G., Nauki Mistrzów, przeł. J. Łoziński, Poznań 2007.

Taktyki wizualne. Michel de Certeau i obrazy, red. J. Thiel-Jańczuk, Kraków 2016.

Skurtys J., Doświadczenie lektury wobec praktyk codzienności (od afirmacji do kontestacji), „Czytanie Literatury. Łódzkie Studia Literaturoznawcze" 2014.

Skurtys J., Praktyki codziennego oporu. Everyday life studies jako teoria sprzeciwu, [w:] Opór protest - wykroczenie, red. Ł. Janicki, J. Wach, Lublin 2015.

The Certeau Reader, red. I. Buchanan, Manchester 2000.

Wójtowicz A., Kulturowa socjologia religii w perspektywie religioznawstwa porównawczego, „Przegląd Religioznawczy” 2011, nr 3. 